Dokuz Eylül Üniversitesi-Mühendislik Fakültesi

Fen ve Mühendislik Dergisi

Cilt 20, Sayı 60, Eylül, 2018
Dokuz Eylul University-Faculty of Engineering Journal of Science and Engineering Volume 20, Issue 60, September, 2018

\title{
A general scheme to create complex triple helical wire rope model using parametric equations
}

\section{${ }^{1}$ Cengiz ERDöNMEZ}

1 Department of Science, Turkish Naval Academy, National Defense University, 34940 Istanbul. (ORCID: 0000-0002-3196-8466)

(Alınış / Received: 10.03.2018, Kabul / Accepted: 18.04.2018, Online Yayınlanma / Published Online: 15.09.2018)

Keywords Single helical, double helical, triple helical, wire rope model, helical geometry modeling, complex helical modeling.
Abstract: Finite Element Analysis of wire ropes made big influence on researchers last decade. Requirement of an correct 3D wire rope model is the most important issue during analysis. To accomplish such a good model with error free surface representation for helical wires are mostly very difficult even sometimes impossible for some kind of helical shapes. This paper aims to show how to construct such an complicated wire rope model. For this purpose parametric mathematical equations of the single, double and triple wire models are represented. Proposed triple helical wire rope model is constructed by using a code instead of ready use commercial 3D software for material design. The constructed model can be adopted to any analysis tool to find numerical results.

\section{Parametrik denklemleri kullanarak karmaşık üçlü sarmal halat modeli oluşturmak için genel bir şema}

\begin{abstract}
Anahtar Kelimeler Özet: Tel halatlarla ilgili yapılan Sonlu Eleman Analiz çalışmaları Tek helisel, çift helisel, üçlü helisel, tel halat modeli, helisel yapı modeli, karmaşık helisel modelleme. araştırmacılar arasında son on yılda büyük ilgi uyandırmıștır. Analiz çalışmaları sırasında doğru üç boyutlu tel halat modelleri ihtiyacı en önemli gerekliliktir. Böyle yüzey hatalarından arındırılmış bazı helisel șekillerin bir katı modelini oluşturmayı başarmak çoğunlukla çok zor hatta bazı zamanlar imkansız olmaktadır. Makalenin amacı bu tür karmaşık bir tel halat modelinin oluşturulmasını göstermeye çalışmaktır. Bu amaçla tekli, ikili ve üçlü tel halat modellerine ait parametrik matematik denklemler gösterilmiştir. Önerilen üçlü helisel halat modeli tasarımı hazır üç boyutlu tasarım uygulamaları kullanılmadan, özgün olarak geliştirilmiş bir kod yardımıyla oluşturulmaktadır. Tasarlanan model herhangi bir analiz aracına uyumlu hale getirilerek sayısal çözümler elde edilebilir.
\end{abstract}

*Sorumlu yazar: cerdonmez@gmail.com 


\section{Introduction}

Wire rope is a structure formed by a large number of helical wires in different forms such as single, double or triple helices. These type of wires combined in a complex manner to form a composite whole. These structures found usage are in mechanical and civil engineering applications in general such as bridges and lifting. These complex structures are preferred due to their capacity to support large tensile forces with small bending and torsional stiffness. Wire ropes are subjected to large loads which can lead to mechanical fatigue and material degradation. When their usage area are considered such as mining, lifting industry and bridges their failures are directly dangers human life. In addition the other expenses are also become important such as loss of time and money. As a result of their small bending and torsional stiffness it is easy to store and transport them which makes their wide usage possible in many application area.

Many research devoted to the static analysis of wire ropes under axial tensile loading in the literature. The theory of thin rods are described by Love [1] in his treaties on the theory of elasticity. Love mentioned the bending and twisting characteristics of thin rods. The difficulty to make an analytical analysis of rods under the bending and twisting condition is also stressed in his treatise. Later on Timoshenko [2] investigated mechanical behavior of wire ropes under torsion and bending analysis. A linearized form to determine stresses in helical constituent wires are mentioned by Green and Laws in [3]. From the early studies without the help of computers and numerical computations mostly linearizational procedures are preferred in 2D models. Costello et al. has studied different aspects of wire strands and wire ropes in his publications between 1970 and 1980 in [4-7]. Costello applied the theory of elasticity to helical wires in his studies and solved the equilibrium equations described in his book in [8]. In his studies frictionless linear theory is preferred by Costello due to the complicated structure of the equilibrium equations. Different types of wire ropes are investigated such as Wire Strand (WS), Independent Wire Rope Core (IWRC) and Seale type IWRC during his studies.

By the development of computer technology in 1970's Finite Element Method is used to make analysis on wire ropes. The stiffness of wire rope structures can be tailored to provide support and restoring forces. Stiffness and damping are adjusted by varying wire diameter, the number of strands, pre-tensioning and the arrangement of lengths of the wire rope. For this reason wire ropes can be used to absorb shocks, internal or system damping purposes as vibrational isolation over wide ranges of frequencies and amplitudes. This is the one of the early study done by using finite element and commercial software MSC NASTRAN by Cochran et al. [9].

Chiang mentioned the impact of six design factors on the cable axial stiffness and axial stress rises at cable ends and at the middle cross-section using finite element methods. In addition to these main effects, it has been found that the interaction between the helical angle and the boundary condition has an influence on the change in axial stiffness, the stress rise at the loaded end, and the stress rise in the middle cross-section in [10].

Likewise the analysis of the wire ropes model generation researches are taken place in the literature. Andorfer investigated the parametric equation of single and double helical wires in his thesis [11]. Similar study on the geometry is studied by Lee in [12]. He defined the centroidal axis of the double helical wire in a rope wrapped around a 
drum. Wang et al. also studied double helical wire geometry in [13].

Erdönmez and İmrak investigated the frictional effects on [14] using the 3D IWRC geometry and showed the wire-bywire results. The robustness of the present FE method is to give wire-bywire analysis results and enables one to obtain insights of loading through a wire rope. Experimental and theoretical investigation of prestressing steel strand subjected to tensile load and fatigue life determination of rotation resistant steel wire ropes are presented in [15-17].

Lately in 2011 Stanova et al. published two paper about the solid model using single and double helical models as an IWRC in [18], but they only included the single helical meshed model in their finite element analysis model in [19]. The studies generated on the centerline definition of both single and double helical wires mostly rely on the definition of the parametric equations. But for the complex wire rope analysis using commercial codes like ANSYS or ABAQUS, it is mandatory to have a defect free 3D solid model with an accurate mesh. At this point wire rope models brings difficulties for their complicated geometry especially using higher order helical centerlines such as double and triple.

In this paper the way of constructing defect free 3D mesh generation of wire ropes is represented. First of all the single, double and triple helical wire parametric mathematical equations are described. Secondly the construction of the 3D structured solid model of wire rope is explained. Thirdly the generation of the mesh with code is explained. Finally some of the constructed example models are represented which are ready to use in the analysis.

\section{Parametric Equations of Helical} Wire Centerlines

The basic parts of a wire ropes depending of the type of rope are a straight wire, a single helical wire, a double helical wire and a triple helical wire. For 3D modeling of these wires, centerlines have to be created at first. For this reason parametric mathematical equations of these centerlines are defined using their parametric equations.

\subsection{Single helical centerline}

The centerline of a straight wire is obvious. For the single helical wire centerline, pitch length is the dominant factor. Helix angle $\alpha_{2}$ is determined by using the related equation of pitch length of $p_{2}$ with solving the equation $\tan \alpha_{2}=p_{2} / 2 \pi r_{2}$ using $r_{2}=R_{1}+R_{2}$ where $R_{1}$ represents the radius of a straight core wire and $R_{2}$ shows the radius of the single helical wire as shown in Figure (1). The parametrical equation of an single helical wire is presented in Equation (1).

$$
\begin{aligned}
& x=r_{2} \cos \theta, \\
& y=r_{2} \sin \theta, \\
& z=p_{2} \frac{\theta}{2 \pi},
\end{aligned}
$$

where $\theta$ shows the rotation angle of the single helical wire around the straight core wire.

A typical Wire Strand (WS) which is composed by using seven wires, is constructed by using a straight wire surrounded by 6 single helical wires around is represented in Figure (1).

\subsection{Double helical centerline}

The second type of wires based on helical shape is the double helical wire. Double helical wires are encountered in the composition of an Independent Wire Rope Core (IWRC). This special type of rope is constructed by using a single wire strand as a core strand surrounded by 6 wire strands which are helically wound 
C. Erdönmez / A General Phenomena to Create Complex Triple Helical Wire Rope Model Using Parametric Equations

around the core wire strand. So the centerline of the outer strands became single helical wire while the outer wires of the outer strand of an IWRC became double helical wire as represented in Figure (2).

Modeling issue of double helical wires are found by following a single helical wire as a core wire. For this reason a single helical wire is considered using its parametric form as,

$$
\begin{aligned}
& x_{s}=r_{s} \cos \left(\theta_{s}\right), \\
& y_{s}=r_{s} \sin \left(\theta_{s}\right), \\
& z_{s}=r_{s} \tan \left(\alpha_{s}\right) \theta_{s} .
\end{aligned}
$$

In Equation (2), $r_{s}$ indicates the distance between the center of the straight core wire and the center of the outer strand core wire which is a single helical wire presented in Figure (2), $\alpha_{s}$ shows the helix lay angle of the outer strand and $\theta_{s}$ represents the position angle of the outer strand around the core strand.

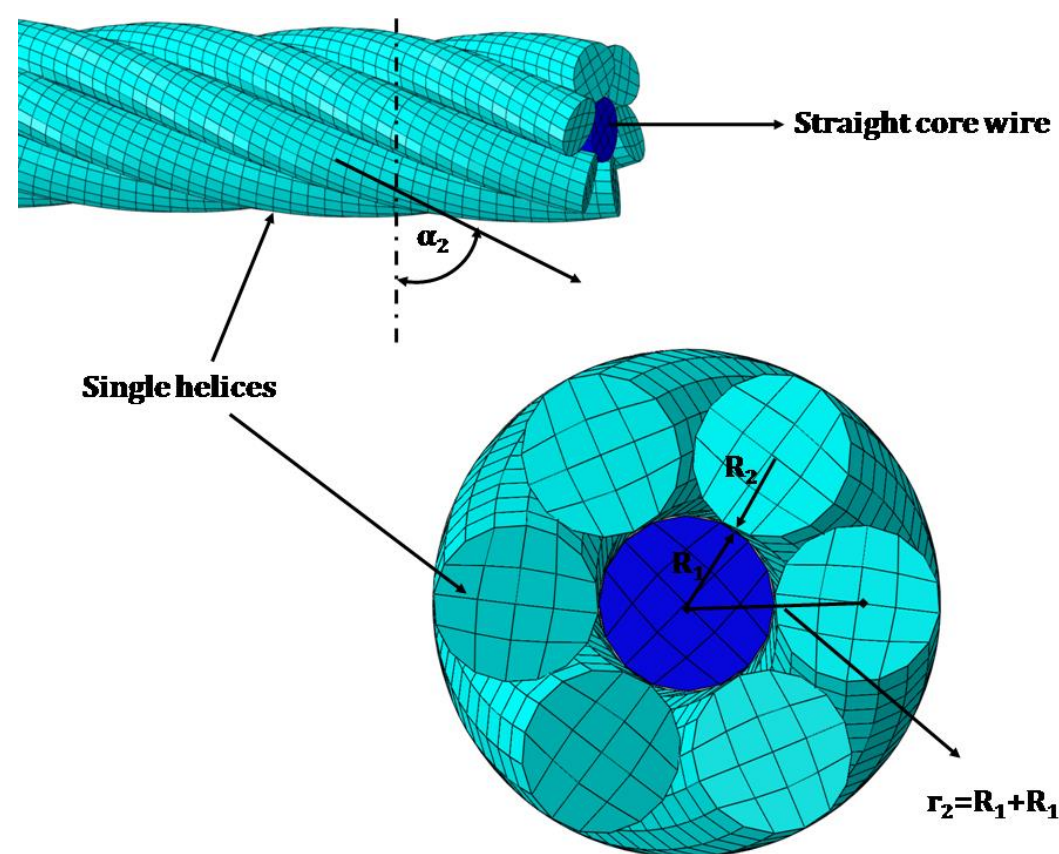

Figure 1. Wire Strand, composed by a straight wire around six single helical wires 
C. Erdönmez / A General Phenomena to Create Complex Triple Helical Wire Rope Model Using Parametric Equations

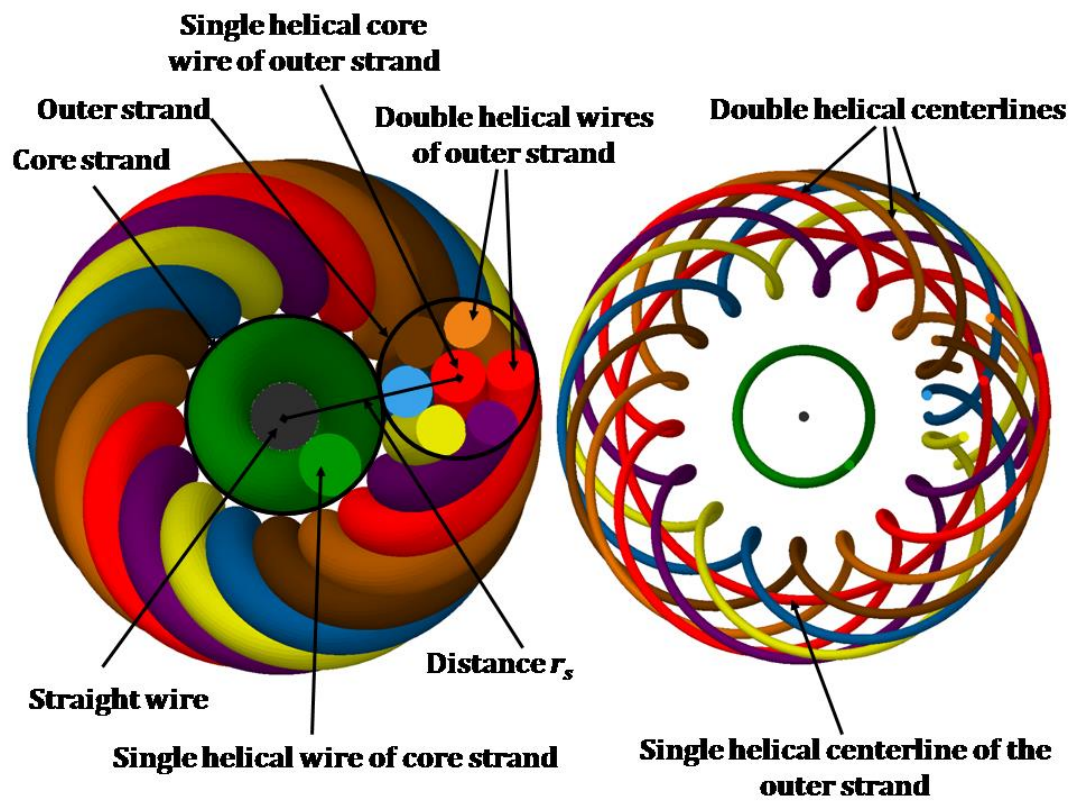

Figure 2. Straight wire, single helical wire and double helical wire used to compose an IWRC.

So the outer wires becomes double helical by wounding around the specified definition of the double helical wire route given in Equation (2). Parametrical centerline is given as,

$x_{d}=x_{s}\left(\theta_{s}\right)+r_{d} \cos \left(\theta_{d}\right) \cos \left(\theta_{s}\right)-r_{d} \sin \left(\theta_{d}\right) \sin \left(\theta_{s}\right) \sin \left(\alpha_{s}\right)$,

$y_{d}=y_{s}\left(\theta_{s}\right)+r_{d} \cos \left(\theta_{d}\right) \sin \left(\theta_{s}\right)+r_{d} \sin \left(\theta_{d}\right) \cos \left(\theta_{s}\right) \sin \left(\alpha_{s}\right)$,

$z_{d}=z_{s}-r_{d} \sin \left(\theta_{d}\right) \cos \left(\alpha_{s}\right)$.

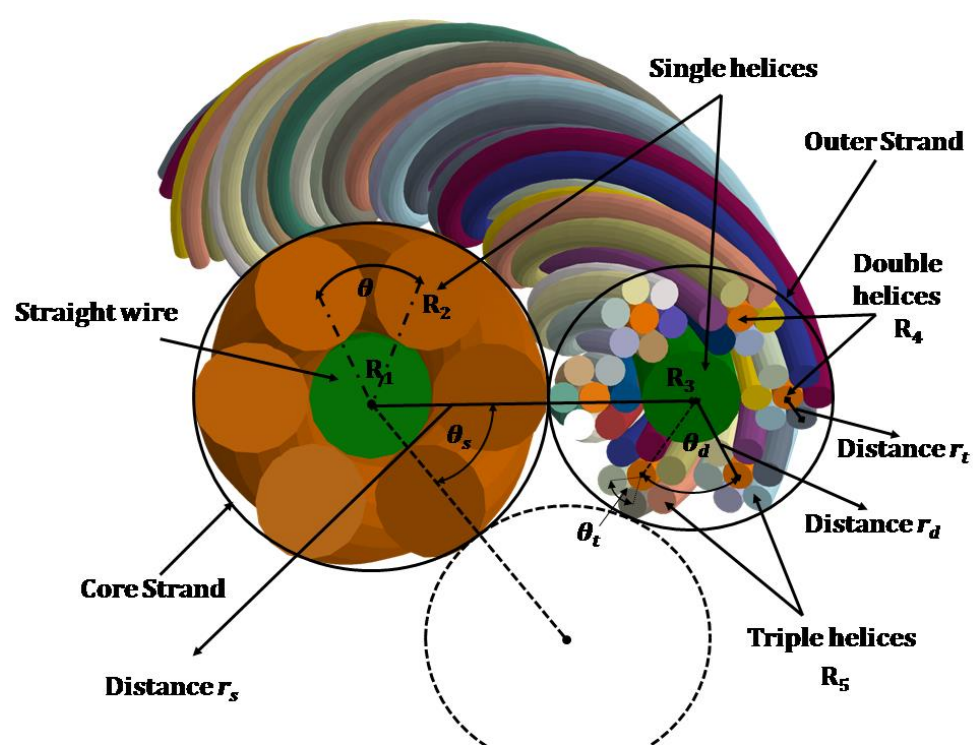

Figure 3. Core and outer strand, wire radiuses, and distances according to rotation centers. 
In Equation (3), $\theta_{d}$ is defined as $\theta_{d}=m \theta_{s}+\theta_{d 0}$ where $\theta_{d 0}$ is the wire phase angle and $r_{d}$ is the distance between the double helix wire centerline and single helix strand centerline. $m$ is the construction parameter and it is estimated by $m=\theta_{d} / \theta_{s}$.

\subsection{Triple helical centerline}

The aim of this part is to define explicitly the parametrical equation of the triple helical centerline. To accomplish this, first of all using the single helical centerline, a double helical centerline is generated. Basically the single helical geometry can be defined as,

$$
\left(\begin{array}{l}
t_{s} \\
n_{s} \\
b_{s}
\end{array}\right)=\left[\begin{array}{ccc}
-\cos \left(\alpha_{s}\right) \sin \left(\theta_{s}\right) & \cos \left(\alpha_{s}\right) \cos \left(\theta_{s}\right) & \sin \left(\alpha_{s}\right) \\
-\cos \left(\theta_{s}\right) & -\sin \left(\theta_{s}\right) & 0 \\
\sin \left(\alpha_{s}\right) \sin \left(\theta_{s}\right) & -\sin \left(\alpha_{s}\right) \cos \left(\theta_{s}\right) & \cos \left(\alpha_{s}\right)
\end{array}\right]\left(\begin{array}{l}
e_{x} \\
e_{y} \\
e_{z}
\end{array}\right) .
$$

A new coordinate system using this TNB frame obtained by single helix centerline is composed as $\left(e_{x^{\prime}}, e_{y^{\prime}}, e_{z^{\prime}}\right)=\left(-n_{s},-b_{s}, t_{s}\right)$

$$
\left(\begin{array}{l}
e_{x^{\prime}} \\
e_{y^{\prime}} \\
e_{z^{\prime}}
\end{array}\right)=\left[\begin{array}{ccc}
\cos \left(\theta_{s}\right) & \sin \left(\theta_{s}\right) & 0 \\
-\sin \left(\alpha_{s}\right) \sin \left(\theta_{s}\right) & \sin \left(\alpha_{s}\right) \cos \left(\theta_{s}\right) & -\cos \left(\alpha_{s}\right) \\
-\cos \left(\alpha_{s}\right) \sin \left(\theta_{s}\right) & \cos \left(\alpha_{s}\right) \cos \left(\theta_{s}\right) & \sin \left(\alpha_{s}\right)
\end{array}\right]
$$

Then double helical geometry $h_{d}$ is composed by using this new coordinate system and the single helical centerline as,

$h_{d}=h_{s}+r_{d} \cos \theta_{d} e_{x^{\prime}}+r_{d} \sin \theta_{d} e_{y^{\prime}}$ which can be represented in matrix form as,

where $r_{d}$.is the distance between core single helical wire of the outer strand to the double helical wire as shown in Figure (3). Rewriting Equation (7) gives the centerline of the double helical geometry $h_{d}=\left(x_{d}, y_{d}, z_{d}\right)$ as,

$x_{d}=x_{s}\left(\theta_{s}\right)+r_{d} \cos \left(\theta_{d}\right) \cos \left(\theta_{s}\right)-r_{d} \sin \left(\theta_{d}\right) \sin \left(\theta_{s}\right) \sin \left(\alpha_{s}\right)$,

$y_{d}=y_{s}\left(\theta_{s}\right)+r_{d} \cos \left(\theta_{d}\right) \sin \left(\theta_{s}\right)+r_{d} \sin \left(\theta_{d}\right) \cos \left(\theta_{s}\right) \sin \left(\alpha_{s}\right)$,

$z_{d}=z_{s}\left(\theta_{s}\right)-r_{d} \sin \left(\theta_{d}\right) \cos \left(\alpha_{s}\right)$,

where $\theta_{d}$ is the double helical rotation

angle. This angle is defined as,

$\theta_{d}=\left(r_{s} \theta_{s}\right) /\left(r_{d} \tan \alpha_{d} \cos \alpha_{s}\right)$. 


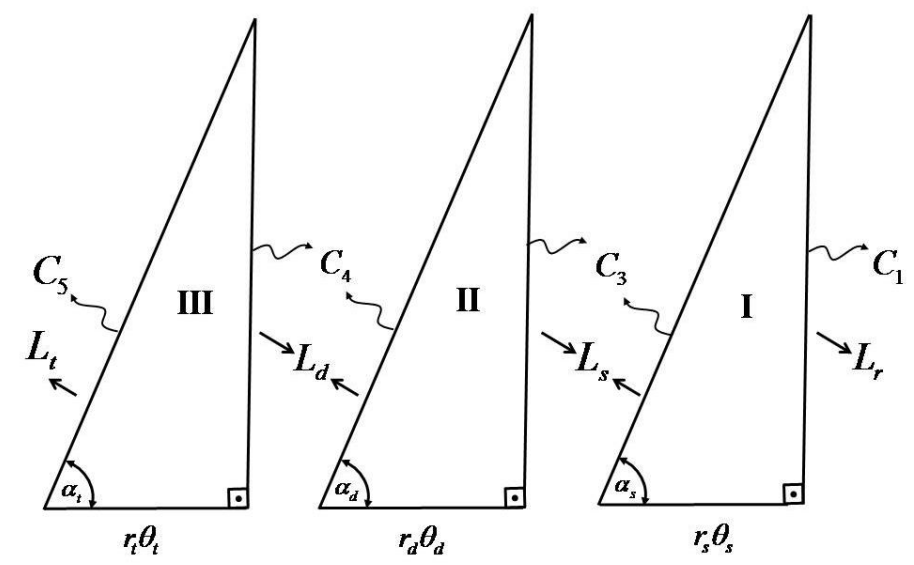

Figure 4. Relations between single, double and triple helices with respect to their lengths.

To compose the triple helical centerline the same method is used recursively. Double helical centerline $h_{d}$ used to find a new TNB frame as $\left(e_{x^{\prime \prime}}, e_{y^{\prime \prime}}, e_{z^{\prime \prime}}\right)=\left(-n_{d},-b_{d}, t_{d}\right)$. The relation between single, double and triple helical wires are given in Figure (4) by using triangles. The relation between length of the rope $L_{r}$ and the length of the single helix $L_{s}$ obtained by using triangle (I) given in Figure (4) as,

$L_{r}=r_{s} \theta_{s} \tan \alpha_{s}$

$L_{s}=\frac{r_{s} \theta_{s}}{\cos \alpha_{s}}$

Similarly the relation between length of the single helix $L_{s}$ and the length of the double helix $L_{d}$ obtained by using triangle (II) given in Figure (4) as,

$L_{s}=r_{d} \theta_{d} \tan \alpha_{d}$

$L_{d}=\frac{r_{d} \theta_{d}}{\cos \alpha_{d}}$

At the end of this procedure the relation between length of the double helix $L_{d}$ and the length of the triple helix $L_{t}$ obtained by using triangle (III) given in Figure (4) as,
$L_{d}=r_{t} \theta_{t} \tan \alpha_{t}$

$L_{t}=\frac{r_{t} \theta_{t}}{\cos \alpha_{t}}$.

where $\theta_{s}, \theta_{d}$ and $\theta_{t}$ represents the single, double and triple helix rotation angles respectively. The relation between the triple helix rotation angle $\theta_{t}$ and double helical rotation angle $\theta_{d}$ can be written by using Equation (13) and Equation (14) as follows,

$\theta_{t}=\frac{r_{d} \theta_{d}}{r_{t} \tan \alpha_{t} \cos \alpha_{d}}$

Using the triple helical rotation angle given in Equation (16) and using the centerline of the double helix, the following equation for triple helical centerline $h_{t}$ is obtained as,

$h_{t}=h_{d}+r_{t} \cos \theta_{t} e_{x^{\prime \prime}}+r_{t} \sin \theta_{t} e_{y^{\prime \prime}}$

where $r_{t}$ shows the distance between the triple and double helix centerlines as in Figure (3). By the way definition of the TNB frame $\left(e_{x^{\prime \prime}}, e_{y^{\prime \prime}}, e_{z^{\prime \prime}}\right)$ which is used in Equation (17), requires necessary derivations using the double helical 
centerline $h_{d}$ symbolically. To derive the analytical form of TNB frame using double helical centerline $h_{d}$, symbolic mathematical software Maple is used and it has been observed that just the tangential part of the TNB frame is becoming very lengthy and not practical to represent the equations due to their lengths here. Instead TNB frame is computed and used during computations of triple helical centerline directly in Matlab. As a result using the centerline defined in Equation (17) triple helical wire is created. The complete wire rope created using straight wire R1, single helical wires R2 and R3, double helical wire R4 and triple helical wire R5 is presented in Figure (5). The complete meshed model of the wire rope including triple helical geometry is presented in Figure (6). In Figure (7) view cut of the wire rope according to the $\mathrm{z}$-axis is presented. This view cut shows us that the cross sections of the wires along the $\mathrm{z}$-axis becomes elliptical as expected.
To construct a real 3D wire rope model is an difficult issue using even today's commercial softwares except simple straight wire strand models using single helices. The problem is the complicated process of wounding one helix over another. In this recursive issue centerlines becomes complicated forms to construct a wire mesh over it using extrusion tools. Even if one could obtain the solid structure of the wire rope using a commercial software then there are other difficulties such as to create a smooth mesh over the solid geometry. For this reason in this paper the construction of the centerline equations for a more complicated form of triple helical structure is derived using parametric mathematical form. Relations between single, double and triple helical wire centerlines are mentioned and 3D meshed form of the triple helical wire is presented. This model can be used for constructing any kind of wire rope model for using structural analysis via Finite Element Analysis codes.

\section{Discussion and Conclusion}

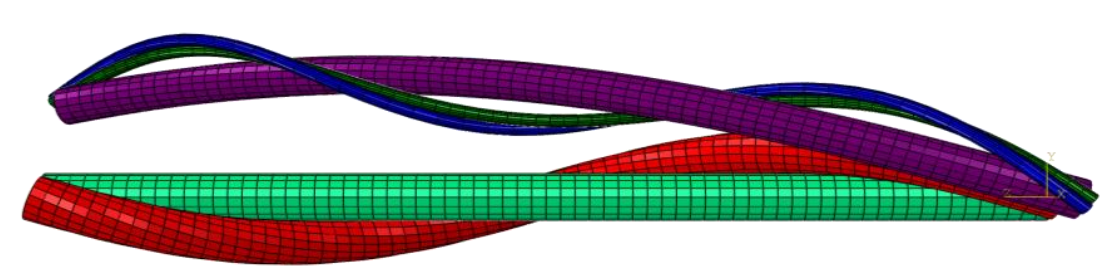

Figure 5. Nested structure of different type of wires together: straight, single helical, double helical and triple helical wires 


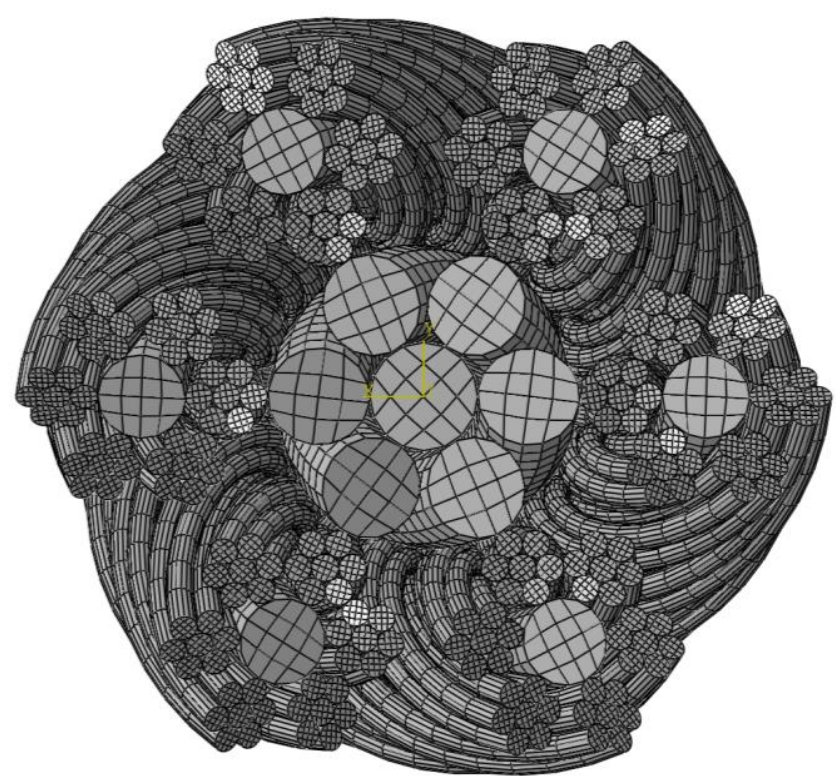

Figure 6. The complete meshed model of the wire rope with using triple helical structure

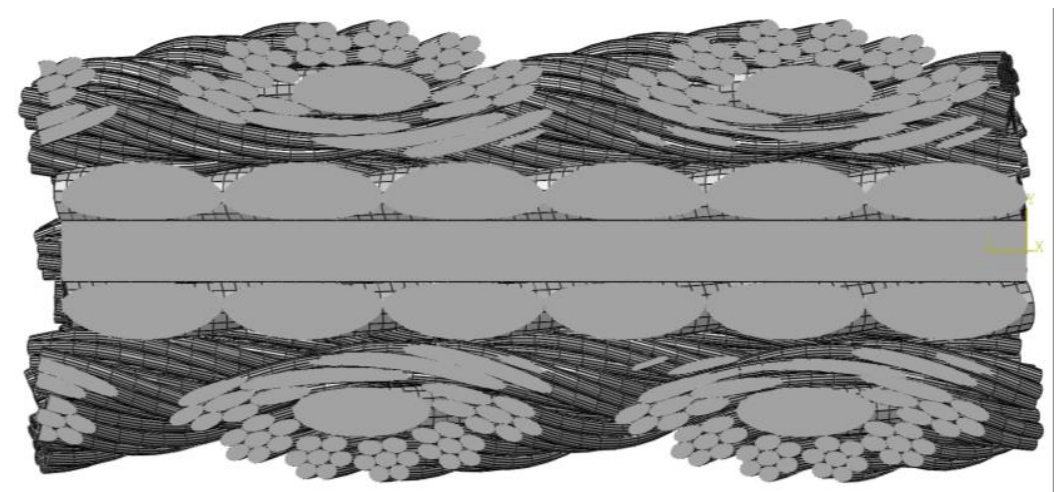

Figure 7. View cut of the wire rope according to the z-axis shows the elliptic cross sections within wire rope

\section{References}

[1] Love AEH (1944) A treatise on the mathematical theory of elasticity, 4th ed., New York: Dover Publ., First Am. Print. 1944, Chapter XVIII-XIX, 381-426.

[2] Timoshenko S (1955) Strength of materials, New York: Van Nostrand, 2:292-299.

[3] Green AE, Laws N (1966) A general theory of rods. Proc. R. Soc. Lond., Ser. A, Math. Phys. Sci., 293:(1433):145-155.
[4] Costello, G.A. and Sinha S.K. Static Behaviour of Wire Rope, Proceedings ASCE, Journal of Engineering Mechanical Division, 103 (No.EM6), 1011-1022, 1977

[5] Costello, G.A. and Miller, R.E. Lay Effect of Wire Rope, Journal of Engineering Mechanical Division, 105 (No.EM4 paper 14753), 597 608, 1979

[6] Costello, G.A. and Butson, G.J. A simplified bending theory for wire rope, Journal of the Engineering Mechanical Division, ASCE, 108, 
C. Erdönmez / A General Phenomena to Create Complex Triple Helical Wire Rope Model Using Parametric Equations

(EM2, Proc. Paper 16984), 219227, 1982

[7] Costello, G.A. and Miller, R.E. Static response of reduced rotation rope, Journal of Engineering Mechanical Division, 106 (No.EM4 paper 15612), 623-631, 1980

[8] Costello GA (1990) Theory of wire rope, Berl.: Springer.

[9] Cochran JE Jr, Fitz-Coy NG, Cutchins MA (1987) Finite element models of wire rope for vibration analysis. NASA Marshall Space Flight Cent., NTRS: 2007-06-26, Number: $\quad 87 N 22748 ; \quad$ ID: 19870013315.

[10] Chiang YJ (1996) Characterizing simple stranded wire cables under axial loading. Finite Elem. Anal. Des., 24:49-66.

[11] Andorfer K (1983) Die Zugkraftverteilung in schwingend beanspruchten geraden Drahtseilen, Diss. Tech. Univ. Graz.

[12] Lee WK (1991) An insight into wire rope geometry. Int. J. Solids Struct., 28:(4):471-490.

[13] Wang RC, Miscoe AJ, McKewan WM (1998) Model for the Structure of Round-Strand Wire Ropes. U.S. Dep. Health Hum. Serv., Public Health Serv., Cent. Disease Control Prev., Natl. Inst. Occup. Saf. Health, DHHS (NIOSH), Publ. No. 98-148, Rep. Investig. 9644:1-19

[14] Erdönmez, C., İmrak, C. E. (2011) A finite element model for independent wire rope core with double helical geometry subjected to axial loads, Sadhana,36(6), pp. 995-1008.

[15] Onur, Y.A. (2016) Experimental and theoretical investigation of prestressing steel strand subjected to tensile load, International Journal of Mechanical Sciences, Vol. 118, pp. 91-100.

[16] Onur, Y.A., İmrak, C.E., Onur, T.Ö. (2017) Investigation on bending over sheave fatigue life determination of rotation resistant steel wire rope, Experimental Techniques, 41(5), pp. 475-482.

[17] Onur, Y.A., İmrak, C.E. (2017) Discard fatigue life of stranded steel wire rope subjected to bending over sheave fatigue, Mechanics \& Industry, 18 (2), 223.

[18] Stanova, E., Fedorko, G., Fabian, M., Kmet, S., Computer modelling of wire strands and ropes Part I: Theory and computer implementation, Advances in Engineering Software, 42(6):305315.

[19] Stanova, E., Fedorko, G., Fabian, M., Kmet, S., Computer modelling of wire strands and ropes part II: Finite element-based applications, Advances in Engineering Software, 42(6):322-331. 